\title{
Effect of Paired Stenosis on Blood Flow through Small Artery
}

\author{
Musad Mohammed Musad Saleh \\ Dpartment of Mathematics University of Pune \\ Pune-411007, Maharashtra, India \\ E-mail: almusaediy@yahoo.com \\ Mear Yaseen Ali Khan \\ Department of Mathematics Poona Collage of Arts, Sciences Commerce \\ Pune-1, India \\ E-mail: khanmyak@yahoo.com
}

Received: January 4, 2011 Accepted: January 21, 2011 doi:10.5539/jmr.v3n2p224

\begin{abstract}
In this paper the mathematical models have been developed to study the effect of paired stenosis on blood flow, where the blood flow is assumed to behave like a couple stress fluid, peripheral layer plasma (Newtonian fluid) and core layer of suspension of erythrocytes (Non- Newtonian fluid). The study predicts that wall shear stress increases with the increase of the two heights of stenosis. Also wall shear stress has proportional direction relation with the separation factor, the maximum value of wall shear stress occurs at the peak separation of paired stenoses.
\end{abstract}

Keywords: Paired stenosis, Blood flow of two layers, Wall shear stress, Newtonian fluid, Cossan fluid

\section{Introduction}

The blood flow through small arteries or arteries with stenosis is considered non-Newtonian Chan et al 2005, Mann and Tarbe 1990, Shukla et al 1980 and Nakamura and Sawada 1988. Non -Newtonian flow is the flow that does not obey the Newtonian relationship between shear stress and shear rate. In non Newtonian flow the slope of shear stress versus shear rate curve is not constant and the viscosity of fluid decreases with increasing shear rate. Wall shear rate of non Newtonian is considered less than 100 s-1 Tu and Delwille 1996, Misra et al 1993, Shukla et al 1990 and Huang et al 1987. The simple example of a liquid exhibiting non-Newtonian flow is paints and printing inks. The simple constitutive equation is Cossan which is based on a structure model of the interactive behavior of solid and liquid phases of two-phase suspension. The model describes the flow of viscoplastic fluids that can be mathematically described as flow. $\sqrt{\tau}=\sqrt{\tau_{y}}+\sqrt{k . \gamma}$, where $\tau$ is shear stress, $\gamma$ is shear rate and $\mathrm{k}$ is a Cossan model constant. The abnormal and unnatural growth in the arterial wall thickness that develops at various location of the cardiovascular system under diseased conditions is called arteriosclerosis or stenosis, this can cause serious circulatory disorders by reducing of occluding the blood supply. For instance stenosis in the arteries supplying blood to brain can bring about cerebral strokes, likewise in coronary arteries it can cause myocardial infarction leading to the heart failure. The actual causes of the stenosis are not well known but it has been suggested that the deposits of the cholesterol on the arterial wall and the proliferation of connective tissues may be responsible. Ponalagusamy 2007 and Srivastava 2003 have assumed blood flow through stenosis to behave like a couple stress fluid, peripheral layer plasma Newtonian fluid which acceptable for high shear rate flow $(\gamma>100$ sec-1) in layer arteries and with viscosity coefficients $\mu_{p}$, and a core region of suspension of erythrocytes non-Newtonian fluid which acceptable for low shear rate flow $\left(\gamma<100\right.$ sec-1) through small diameter arteries and with viscosity coefficients $\mu_{c}$, Sanker and Ahmmed 2009 have assumed the non-Newtonian fluid in core layer as Casson fluid and indicated that Casson fluid model holds for blood flow in tubes of diameter $0.013-0.13 \mathrm{~cm}$ also estimated the range of wss $1.677-2.290$ for hieght stenosis range $0.025-0.125$.

The initiation and localization of arteriosclerosis is closely related to local hemodynamic factor (such as wall shear stress, hydrostatic pressure and dynamic pressure). Wall shear stress is an important factor in the study of blood flow. Accurate predictions of the distribution of the wall shear stress are particularly useful for the understanding of the effect of blood flow on endothelial cells. Musad and Khan 2010 have developed mathematical models to study wall shear stress in larg and small artery with single stenosis. Thus in this paper we extend the models to study blood flow through artery with paired stenosis. Johnston and Kilpatrick 1990 have considered a mathematical model of paired stenosis. The two velocities of both layers have reported by Kapur 1985 .

\section{The Model Devloped}

Consider an axially symmetric flow of blood which assumed to be incompressible in the two directions through a rigid walled artery with an axially symmetric paired stenosis. Also we consider the flow of a plasma layer and a core layer with 
viscosity coefficient $\mu_{p}$, and $\mu_{c}$ respectively, we also assume that the plasma layer is of uniform thickness and $\delta_{1}, \delta_{2}$ are the hight of stenosis 1 and stenosis 2 respectively

The velocity of plasma layer (Newtonian fluid) and the geometry equation of the stenosis are given by

$$
\begin{aligned}
& v_{p}=\frac{G}{4 \mu_{p}}\left(R^{2}(z)-R^{2}\right), 0<R<R(z)
\end{aligned}
$$

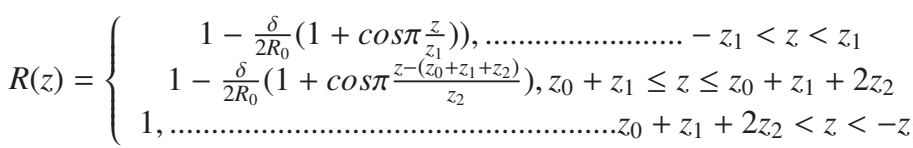

Also the velocity of core layer (non-Newtonian fluid ) is given by

$$
v_{c}=\frac{G}{4 \mu_{c}}\left[R^{2}(z)-r^{2}\right]+\frac{G}{\mu_{c}}\left[R^{2}(z)-R_{1}^{2}(z)\right]\left[\frac{\mu_{c}}{\mu_{p}}-1\right], 0<r \leq R_{1}(z)
$$

While the geometry equation of core layer is $R_{1}(z)=\beta R(z)$, where $(0<\beta<1)$

Since blood flow in peripheral is Newtonian, then wall shear stress is given by the equation

$$
\tau_{p}=-\mu_{p} \frac{\partial v}{\partial r}
$$

Where $\tau$ is the shear stress, $\mu_{p}$ is the viscosity of plasma, $\partial v / \partial r$ is the velocity gradient or rate of deformation (shear rate), $\mathrm{v}$ is the velocity, $\mathrm{G}$ is the pressure gradient and $\mathrm{R}(\mathrm{z})$ is the radius of artery in the stenosis part and $R_{0}$ is the radius of normal part of artery then

Derivative(1), then

$$
\left(\frac{\partial v}{\partial r}\right)_{r=r(z)}=\frac{\partial v_{p}}{\partial R}=\frac{\partial v_{z}}{\partial R}=\frac{G}{2 \mu_{p}} r(z)
$$

From equations (4) and (5) we get

$$
\tau_{p}=-\frac{G}{2}\left[\int_{-z_{1}}^{z_{1}}\left(1-\frac{\delta_{1}}{2 R_{0}}\left(1+\cos \pi \frac{z}{z_{1}}\right)\right) d z+\int_{z_{0}+z_{1}}^{z_{0}+z_{1}+2 z_{2}}\left(1-\frac{\delta_{2}}{2 R_{0}}\left(1+\cos \pi \frac{z-\left(z_{0}+z_{1}+z_{2}\right)}{z_{2}}\right) d z+\int_{z_{0}+z_{1}+2 z_{2}}^{-z_{1}} d z\right]\right.
$$

By integrating(6) we get

$$
\tau_{p}=\frac{G}{2}\left(z_{0}+\frac{\delta_{1}}{R_{0}} z_{1}+\frac{\delta_{2}}{R_{0}} z_{2}\right)
$$

Equation (7) is the equation of wall shear stress of artery with paired stenoses in the case of blood is Newtonian fluid.

Similarly blood flow in core is non- Newtonian, then wall shear stress is given by the equation.

$$
\sqrt{\tau_{c}}=\sqrt{\tau_{y}}+\sqrt{-\mu_{c} \frac{\partial v}{\partial r}}
$$

The velocity of blood flow in core region is given in equation (3), let $\frac{\mu_{c}}{\mu_{p}}-1=\mu_{m}$ then equation (3) reduce to

$$
v_{c}=\frac{G}{4 \mu_{c}}\left(R^{2}(z)-R_{0}^{2}\right)+\frac{G}{\mu_{c}}\left(R^{2}(z)-R_{1}^{2}(z)\right)\left(\mu_{m}\right) .
$$

Derivative(9), then

$$
\left(\frac{\partial v_{c}}{\partial r}\right)_{r=R(z)}=\frac{G}{2 \mu_{c}}\left[\left(1+4 \mu_{m}\right) R(Z)-4 \mu_{m} R_{1}(z)\right]
$$

from eq(8) and eq(10) we get

$$
\sqrt{\tau}_{c}=\sqrt{-\frac{G}{4}\left[\left(2+8 \mu_{m}\right) \int R(z) d z-8 \mu_{m} \int R_{1}(z) d z\right]}+\sqrt{\tau_{y}}
$$

But $R_{1}(z)=\beta R(z),(0<\beta<1)$ then 


$$
\begin{gathered}
\left(\sqrt{\tau}_{c}=\sqrt{-\frac{G}{4}\left[\left(2+8 \mu_{m}\right) \int R(z) d z-8 \mu_{m} \int \beta R(z) d z\right]}+\sqrt{\tau_{y}}\right) \\
\left(\sqrt{\tau}_{c}=\sqrt{\left.-\frac{G}{4}\left(2+8 \mu_{m}-8 \mu_{m} \beta\right) \int R(z) d z+\sqrt{\tau_{y}}\right)}\right. \\
\sqrt{\tau_{c}=} \sqrt{-\frac{G}{2}\left(1+4 \mu_{m}-4 \mu_{m} \beta\right)\left[\int_{-z_{1}}^{z_{1}}\left(1-\frac{\delta_{1}}{2 R_{0}}\left(1+\cos \pi \frac{z}{z_{1}}\right)\right) d z+\int_{z_{0}+z_{1}}^{z_{0}+z_{1}+2 z_{2}}\left(1-\frac{\delta_{2}}{2 R_{0}}\left(1+\cos \pi \frac{z-\left(z_{0}+z_{1}+z_{2}\right)}{z_{2}}\right) d z+\int_{z_{0}+z_{1}+2 z_{2}}^{-z_{1}} d z\right]+\sqrt{\tau_{y}}\right.}(1) \\
\sqrt{\tau_{c}}=\sqrt{\frac{G}{2}\left(z_{0}+\frac{\delta_{1}}{R_{0}} z_{1}+\frac{\delta_{2}}{R_{0}} z_{2}\right)\left(1+4 \mu_{m}-4 \mu_{m} \beta\right)}+\sqrt{\tau_{y}}
\end{gathered}
$$

put $\beta=0.95$ and substitute $\mu_{m}$ in eq(13)where $\mu_{m}=\left(\frac{\mu_{c}}{\mu_{p}}-1\right)$ then we get

$$
\sqrt{\tau}_{c}=\sqrt{\frac{G}{2}\left(z_{0}+\frac{\delta_{1}}{R_{0}} z_{1}+\frac{\delta_{2}}{R_{0}} z_{2}\right)\left(0.8-0.2 \frac{\mu_{C}}{\mu_{p}}\right)}+\sqrt{\tau_{y}}
$$

Equation (14) is the equation of wall shear stress of artery with paired stenoses in the case of blood is non-Newtonian fluid

\section{Boundary Conditions}

1) $\tau \rightarrow \infty$ at $R_{0}=0$

2) $\tau_{c}=\tau_{p}$ when $\mu_{c}=\mu_{p}$.

3) when $z_{0}=z_{1}+z_{2}$ then

$$
\begin{gathered}
\tau_{p}=\frac{G}{2}\left(\left(z_{1}+\frac{\delta_{1}}{R_{0}} z_{1}\right)+\left(z_{2}+\frac{\delta_{2}}{R_{0}} z_{2}\right)\right) \\
\tau_{p}=\frac{G}{2}\left(z_{1}+\frac{\delta_{1}}{R_{0}} z_{1}\right)+\frac{G}{2}\left(z_{2}+\frac{\delta_{2}}{R_{0}} z_{2}\right) .
\end{gathered}
$$

$\tau_{p}=\tau_{1}+\tau_{2}$

while

$$
\sqrt{\tau}_{c}=\sqrt{\tau_{1}+\tau_{2}}+\sqrt{\tau}_{y} \neq\left(\sqrt{\tau}_{1}+\sqrt{\tau}_{2}\right)+\sqrt{\tau}_{y} .
$$

\section{Results and Conclusion}

The results based on the numerical solution of equation (14) by using mathematical software(Microsoft Mathematics 3.0) for $z_{0}=0, z_{0}=z_{1}=z_{2}$ and $z_{0}=z_{1}+z_{2}$ the values of $\left(\delta_{1} / R_{0}\right)$ and $\left(\delta_{2} / R_{0}\right)$ varied from 0.1 to 0.9 and values of $\left(\mu_{c} / \mu_{p}\right)$ varied from 1 to 2.5 , observed that, wall shear stress has direct relation with the separation factor $z_{0}$ and wall shear stress is maximum at peak separation $z_{0}=z_{1}+z_{2}$. Also wall shear stress increases with the increase of one or both heights of stenosis. Mathematically, we see the peak separation in the case of paired stenoses lead to peak separation of wall shear stress in plasma layer (Newtonian fluid), this mean the vessel of paired stenosis or multiple stenosis have wall shear Stress equals the sum of total stresses for each stenosis, while this does not happen in core layer (non-Newtonian fluid), the viscosity of the blood and the yield stress are not doubled by a doubling of stenosis, but change in a certain range. High stress leads to aggregate blood platelets, which in turn lead to the blocked of vessels.

The results listed in the (Tables 1 and 2) and curves (Figures 1 - 3) show that the wall shear stress rang is (0.1 to 0.52 pa), pressure gradient rang is $(200$ to $300 \mathrm{pa} / \mathrm{m})$, viscosity rang is $(0.004$ to 0,009 pa.-s) and yield stress rang is $(0.01$ to 0.03 pa.).

\section{References}

Chan. W. Y, Ding. Y \& Tu. G. Y. (2007). Modeling of non-Newtonian blood flow through a stenosis artery incorporating fluid-structure interaction, Anziam J. 47. 507-523, [Online] Available: http://anziamj.austms.org.au/ojs/index.php/ANZIA MJ/article/viewFile/1059/1001. 
Huang C. R, Pan W. D, Chen H. W,Copley A. L. (1987). Thixotropic properties of whole blood from healty human subjects, Biorheology, 24 795-801.

Kapur, J. N. (1985). Mathematical Models in Biology and Medicine. Affiliated East-West Press Pvt. Ltd., New Delhi. Chapter 11.

Ponalagusamy, R. (2007). Blood Flow through an Artery with Mild Stenosis: A Two - Layered Model, Different Shapes of Stenoses and Slip Velocity at the Wall, Journal of Applied Sciences, 7 1071-1077.

Peter R. Johnston and David Kilpatrick. (1990). A mathematical model of paired arterial stenoses. Joural of biomechanics, pp 229-230.

Mann, D.E., Tarbell, J.M. (1990). Flow of non-Newtonian blood analog fluids in rigid curved and straig artery models, Biorheology, Vol. 27 711-733.

Misra, J.C., Patra, M.K., Misra S.C. (1993). A non-newtonian fluid model for blood flow through arteries under stenotic conditions, J. Biomechanics, Vol. 26 1129-1141.

Musad M. M and Khan M. Y. A. (2010). Effect of Wall Shear Stess in Blood Flow of Two Layers in the Vessels through Stenosis Region, Journal of Applied Mathematic Sciences Vol. 4, No. 52 pp 2587-2598. [Online] available http://www.mhikari.com/ams/ams-2010/ams-49-52-2010/musadAMS49-52-2010.pdf.

Nakamura, M., Sawada, T. (1988). Numerical study on the flow of a Non-Newtonian fluid through an axisymmetric stenosis, J. Biomech. Engng., Vol. 110, pp. 137-143.

Sankar D. S \& Ahmad Izani Md. (2009). Two fluids mathematical models for blood flow in stenosed arteries: A Comparative study. Hindawi publishing problems, Volume1-15. [Online]available: http://downloads.hindawi.com/journals/bvp/200 9/568657.pdf

Shukla, J. B., Parihar R. S. and Rao, B. R. P. (1980). Effects of Stenosis on Non-Newtonian Flow of the Blood in an Artery, Bulletin of Mathematical Biology, 42, pp. 283-294.

Shukla J. B, Parihar R. S, Gupta S. P. (1990). Biorheological aspects of blood flow through artery with mild stenosis: Effects of peripheral layer. Biorhe. 17 403-410.

Srivastava V.P. (2003). Flow of a couple stress fluid representing blood. [Online] Available: http://www.new.dli.ernet.in/raw dataupload/upload/insa/INSA_1/2000c4ee-1727.pdf

Tu, C., Deville, M. (1996). Pulsatile flow of non-newtonian fluids through arterial stenoses, J. Biomechanics, Vol. 29, 7 , 899-908.

Table 1. Data on wall shear stress $\left(\tau_{c}\right)$ of core layer in the paired stenosis artery for different values of $\frac{\delta_{1}}{R_{0}}, \frac{\delta_{2}}{R_{0}},\left(\mu_{c} / \mu_{p}\right) 1-$ 2.5 and separation factor with respect to the length of both stenosis. $z_{1}=z_{2}=0.0002 \mathrm{~m}, \mathrm{~m}$ and $R_{0}=0.0002 \mathrm{~m}$

\begin{tabular}{cccc}
\hline$\frac{\delta_{1}}{R_{0}}=\frac{\delta_{2}}{R_{0}}$ & $\begin{array}{c}\text { WSS(pa) } \\
\text { at } z_{0}=0\end{array}$ & $\begin{array}{c}\text { WSS (pa) } \\
\text { at } z_{0}=z_{1}=z_{2}\end{array}$ & $\begin{array}{c}\text { WSS (pa) } \\
\text { at } z_{0}=z_{1}+z_{2}\end{array}$ \\
\hline 0.100 & 0.088867 & 0.243046 & 0.345009 \\
0.188 & 0.118931 & 0.264184 & 0.364651 \\
0.277 & 0.145444 & 0.284900 & 0.383994 \\
0.366 & 0.170049 & 0.305259 & 0.403150 \\
0.455 & 0.193414 & 0.325312 & 0.422136 \\
0.544 & 0.215889 & 0.345099 & 0.440969 \\
0.633 & 0.237685 & 0.364651 & 0.459660 \\
0.722 & 0.258942 & 0.383994 & 0.478222 \\
0.811 & 0.279757 & 0.403150 & 0.496664 \\
0.900 & 0.300200 & 0.422136 & 0.514995 \\
\hline
\end{tabular}

$$
1 \mathrm{pa} .=\mathrm{N} / \mathrm{m}^{2}=10 \mathrm{dyn} / \mathrm{cm}^{2}
$$


Table 2. Data on wall shear stress for different values of viscosity and different yield shear stress with peak separation and max. pressure gradient, $R_{0}=z_{1}=z_{2}=0.0002 \mathrm{~m}$ and $\delta_{1}=\delta_{2}=0.0001 \mathrm{~m}$.

\begin{tabular}{ccc}
\hline $\begin{array}{c}\text { Viscosity (pa. s) } \\
\times 10^{-} 3\end{array}$ & $\begin{array}{c}\text { yield stress (pa) } \\
\times 10^{-} 2\end{array}$ & WSS (pa) \\
\hline 4.0 & 1.0 & 0.275 \\
4.5 & 1.2 & 0.292 \\
5.1 & 1.4 & 0.309 \\
5.6 & 1.6 & 0.326 \\
6.2 & 1.9 & 0.342 \\
6.7 & 2.1 & 0.358 \\
7.0 & 2.3 & 0.373 \\
7.8 & 2.5 & 0.389 \\
8.4 & 2.7 & 0.404 \\
9.0 & 3.0 & 0.419 \\
\hline \multicolumn{3}{c}{$1 \mathrm{pa} .=N / \mathrm{m}^{2}=10 \mathrm{dyn}^{2} \mathrm{~cm}^{2}$} \\
\hline
\end{tabular}

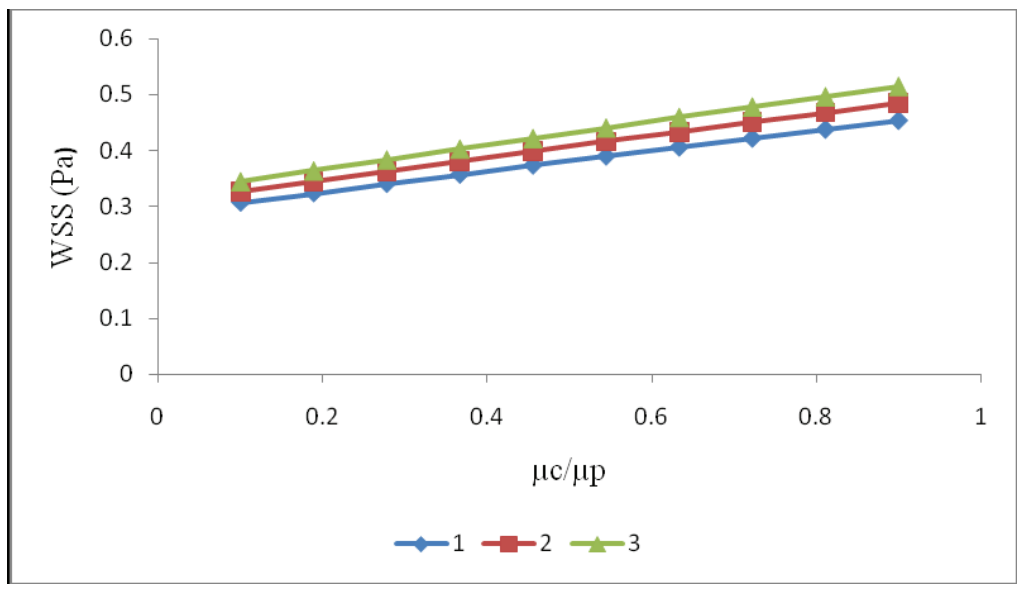

Figure 1. Effect of height stenosis on wss with (1) $\mu \mathrm{c} / \mu \mathrm{p}=1$, (2) $\mu \mathrm{c} / \mu \mathrm{p}=1.5, \mu \mathrm{c} / \mu \mathrm{p}=2$ an (3) $\mu \mathrm{c} / \mu \mathrm{p}=2.5$

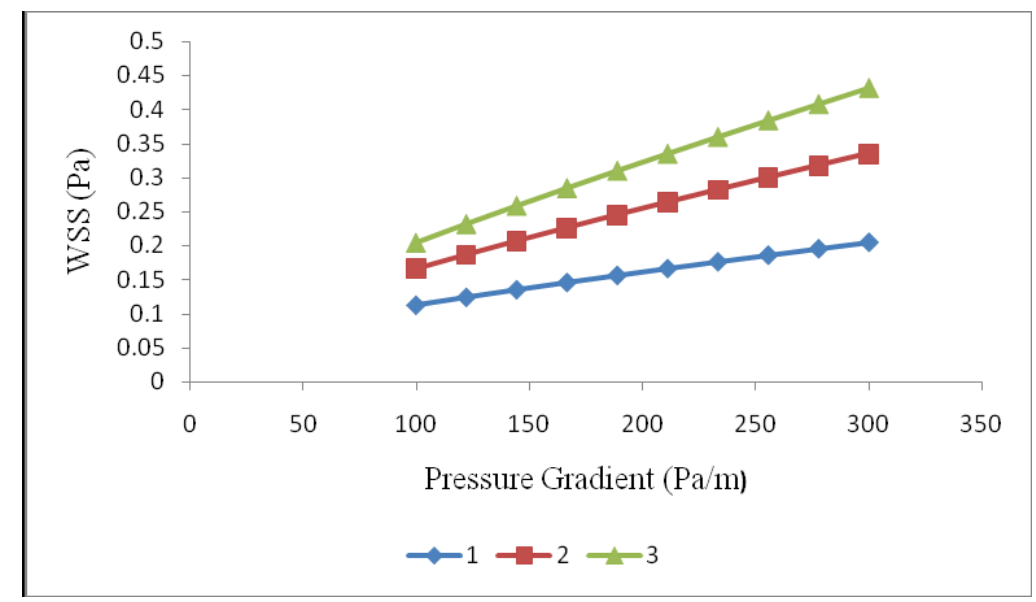

Figure 2. Effect of pressure gradient on wss with different values of seperation factor, $\mathrm{z}_{0}=0.0002 \mathrm{~m}, \mathrm{z}_{0}=0.0003 \mathrm{~m}$ and $\mathrm{z}_{0}$ $=0.0004$ 


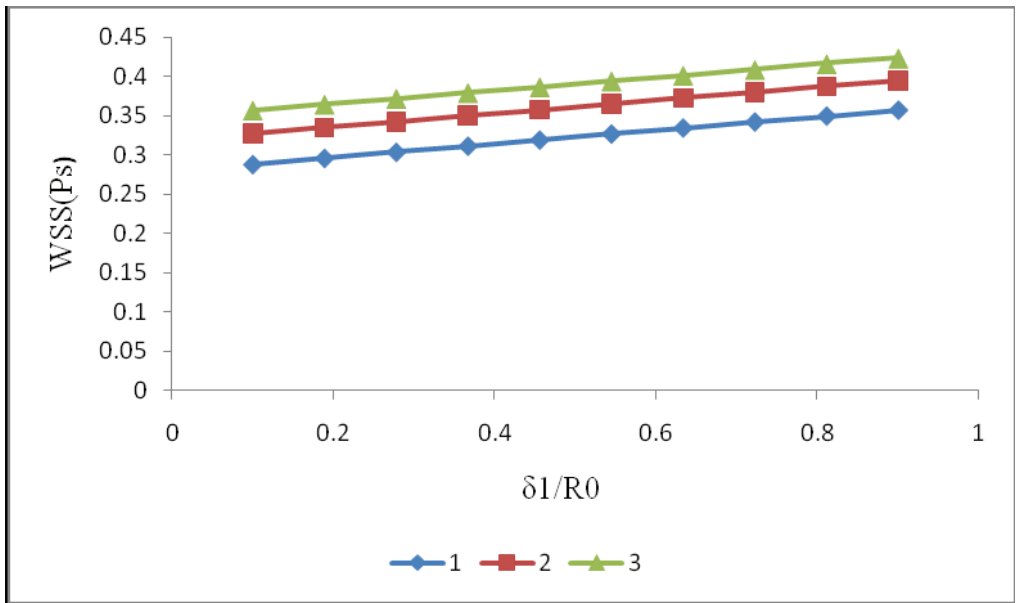

Figure 3. Effect of $\delta_{1} / \mathrm{R}_{0}$ on wss with deferent values of $\delta_{2} / \mathrm{R}_{0},\left(\delta_{2} / \mathrm{R}_{0}=0.1, \delta 2 / \mathrm{R}_{0}=0.5\right.$ and $\left.\delta_{2} / \mathrm{R}_{0}=0.9\right)$ at beg separation $\mathrm{z}_{0}=\mathrm{z}_{1}+\mathrm{z}_{2}$

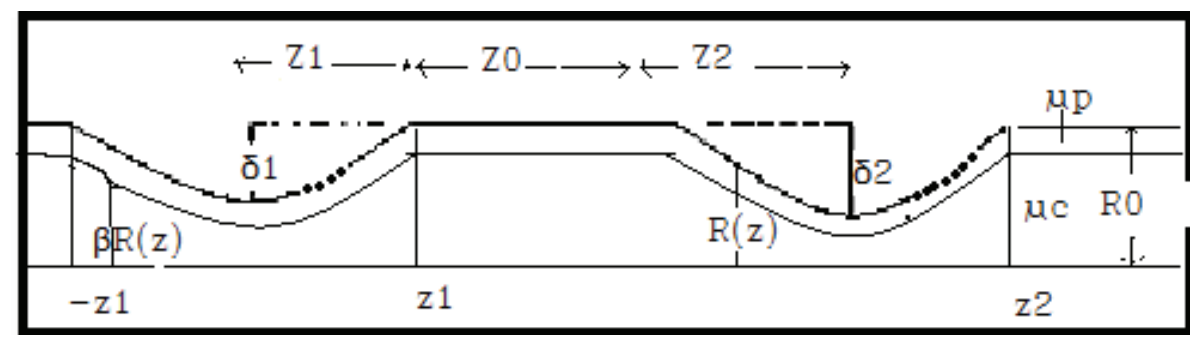

Figure 4. Physical Model and Coordinates System of Paired Stenosis 